\title{
PRAKTIK BERORIENTASI SOFT SKILLS DENGAN PENDEKATAN INDUSTRIAL CULTURE BASED GEMBA KAIZEN MODEL
}

\author{
Walan Yudiani, Edi Siregar*) \\ *)Dosen Tetap Program S1 Jurusan Manajemen Fakultas Ekonomi Universitas Satya Negara Indonesia \\ Wyudiani@yahoo.com; edisiregarusni@gmail.com
}

\begin{abstract}
The research objective is to design learning model with orientation capability increase student soft skills. The data collection method used observation, tests and self-assessment. While data analysis using bar charts, check sheets and line charts. Based on the results of data analysis there are several important findings include that the implementation of practice learning through projectbased learning approach based industrial culture Gemba Kaizen model of the first cycle and cycle II and III provide a positive response to the formation of students soft skills evidenced by the increase in soft skills mastery significantly with the result that more dominant on communication skills and report writing skills then successively on professional and problem solving skills, personal quality and teamwork skills.
\end{abstract}

Keywords: Project Based Learning, Soft Skills, Industrial Culture, Gemba Kaizen Model.

\section{PENDAHULUAN}

Pendidikan karakter yang baik harus melibatkan bukan saja aspek pengetahuan yang baik (moral knowing), tetapi juga merasakan dengan baik atau loving good (moral feeling), dan perilaku yang baik (moral action). Pendidikan karakter menekankan pada kebiasaan yang terus-menerus dipraktikkan dan dilakukan. Jika ingin beradaptasi dengan dunia industri kembangkan dan bangun nilai-nilai soft skills sebagai budaya sekolah. Aspek soft skills masuk dalam ranah pembentukan budaya dan karakter seorang.

Soft skills menurut Baroto (2014) diantaranya dengan mengembangkan Industry Culture pada konsep Gemba Industry dengan kompetensinya: kemampuan komunikasi verbal, menulis laporan dengan baik, teamwork, profesional dibidangnya, dan mampu memecahkan masalah. Work Book NWT Literacy Council dalam Soft Skills for Work (2012), ada 4 kategori dalam soft skills diantaranya: Personal Qualities: pribadi yang berkualitas seperti merasa baik tentang diri sendiri dan pekerjaannya, bertanggung jawab, bersikap sopan, dan menjadi termotivasi untuk melakukan pekerjaan terbaik.

Communication Skill merupakan keterampilan komunikasi mencakup kemampuan berbicara, mendengarkan dengan baik, memberi dan memahami instruksi, berkomunikasi dalam cara-cara sesuai dengan situasi dan audiennya. Teamwork Skill: keterampilan kerja sama tim adalah dapat bekerja baik dengan orang lain, berpartisipasi sebagai anggota tim menyelesaikan konflik yang berat. Problem Solving Skill: kemampuan memecahkan masalah dengan melakukan identifikasi masalah, perumusan dan evaluasi dengan berbagai solusi alternatif terhadap masalah dengan resiko berat sekalipun dan menguntungkan dengan tidak sia-sia dalam pekerjaannya. Studi yang dilakukan oleh Mitsubishi Research Institut (2002) menyebutkan bahwa, kesuksesan lulusan, ternyata tidak ditentukan oleh kemampuan teknis dan akademis, namun $40 \%$ disumbang oleh kematangan emosi dan sosial (soft skills), 30\% oleh proses networking yang dijalin, $20 \%$ oleh kemampuan akademis, dan 10\% oleh kemampuan finansial yang dimilikinya.

\section{LANDASAN TEORI}

Abduwani (2012) pada studi kasus di Oman dalam temuannya menyatakan pentingnya soft skills pada dunia kerja yang memberikan kekuatan untuk tetap bekerja dan motivasi tinggi. Dalam penelitiannya, bahwa para pekerja di bank mempunyai orientasi soft skills lebih baik dibandingkan dengan para pekerja di perminyakan. Negoro (2014) menyoroti permasalahan tamatan SMK yang tidak memenuhi SKKNI, SMK tidak demand dan bidang-bidang kompetensi lulusan SMK tidak selaras dengan kompetensi industri. 
Siswa putus kerja SMK Kampung Jawa pada tiga tahun terakhir ini rata-rata $60 \%$ mereka belum siap bekerja. Dengan alasan kondisi kerja yang berat seperti; tekanan kerja yang terlalu tinggi, belum sanggup bekerja lembur dan memahami kerja dengan target waktu yang ditetapkan, terlalu jauh lokasi tempat kerja dari tempat tinggal dan cepat bosan dalam pekerjaan. Sisanya $40 \%$ tetap bekerja. Sehingga siswa lulusan SMK Kampung Jawa dapat dikatakan belum siap secara fisik dan mental menghadapi dunia kerja. Dipertegas pula laporan data perekrutan calon karyawan PT. Griya Miesejati (Bakmi GM) dari siswa SMK Kampung Jawa per periode 2012-2014 dari 50 peserta ikut tes yang berhasil hingga menjadi karyawan tidak lebih dari $8 \%$. Hal ini juga berkaitan dengan kurangnya soft skills siswa sehingga alasan inilah peneliti untuk memperlakukan improvement melalui penelitian tindakan kelasnya terhadap kegiatan pembelajaran dengan mengorientasikan soft skills sebagai treatment pembelajaran praktik di SMK Kampung Jawa.

Tambahnya pula selama ini sekolah sudah melakukan berbagai macam perbaikan pembelajaran baik melalui beberapa pendekatan, strategi dan model belajar hanya saja tidak pada konten soft skills hanya peningkatan hasil belajar dalam pencapaian keterampilan, pengetahuan dan sikap saja. Laporan penelitian tindakan kelas peneliti menunjukkan bahwa model belajar tutor sebaya dapat meningkatkan hasil belajar praktik hingga tuntas sampai dengan 85\%. Yudiani (2010) dalam penelitian yang lain menyatakan bahwa pemanfaatan media blog pada siswa-siswa yang mengikuti kegiatan praktik kerja lapangan (PKL) mengalami kenaikan hingga $80 \%$ hasil belajar teori kejuruannya. Yudiani (2012) menyatakan bahwa kegiatan pembelajaran Backward Design $C B E^{+}$berbasis $U b d$ dapat meningkatkan pemahaman prosedur praktik otomotif hingga $95 \%$. Untuk menjawab permasalahan perlu dilakukan perbaikan pembelajaran dengan pembelajaran praktik berorientasi soft skills dengan pendekatan industry culture based gemba kaizen model.

\section{METODOLOGI PENELITIAN}

\section{Populasi dan Sampel Penelitian}

Populasi adalah kesuluruhan subyek penelitian. Populasi dalam penelitian ini adalah siswa SMK Kampung Jawa berjumlah 423 siswa. Sementara sampling menurut Arikunto (1998) sebagian dari populasi yang akan diteliti. Teknik sampling yang digunakan pada penelitian adalah teknik sampling purposive yaitu sampling yang diikutsertakan karena ada sesuatu hal yang purposive seperti di SMK Kampung Jawa samplingnya adalah siswa kelas XII TKR yang berjumlah 58 siswa dengan tujuan akan disiapkan untuk bekerja di dunia industri.

\section{Teknik Pengumpulan Data}

Data yang diperlukan dalam penelitian ini adalah data mengenai soft skills siswa dalam rangka mengikuti pembelajaran praktik melalui project based learning dengan pendekatan genba kaizen model. Pengumpulan data dalam penelitian ini dilakukan dengan beberapa cara:

1. Observasi: Kegiatan siswa terutama penerapan kaizen, 5S dan kerja tim pada saat proses pembelajaran praktik berlangsung.

2. Melalui tes: Siswa diberikan tes perbuatan atau praktik, presentasi (tes lisan) atau membuat laporan kerja (tes tulis) saat berlangsungnya proses pembelajaran praktik.

3. Penilaian diri (Self Assesment): Teknik penilaian dengan cara meminta siswa untuk menilai dirinya sendiri. Dalam penelitian ini siswa diminta menilai dirinya untuk mengikuti prosedur kesehatan dan keselamatan kerja (K3).

\section{Teknik Analisis Data}

Analisis data dilakukan dalam tiga siklus dari siklus I, II dan III dimana hasil tahapan refleksi pada siklus I dijadikan dasar perbaikan pada siklus II. Selanjutnya hasil siklus II dijadikan dasar perbaikan pada siklus III dengan empat tahapan yang sama, yaitu:

1. Tahap Perencanaan

2. Tahap Pelaksanaan Tindakan

3. Tahap Analisis

4. Tahap Refleksi 


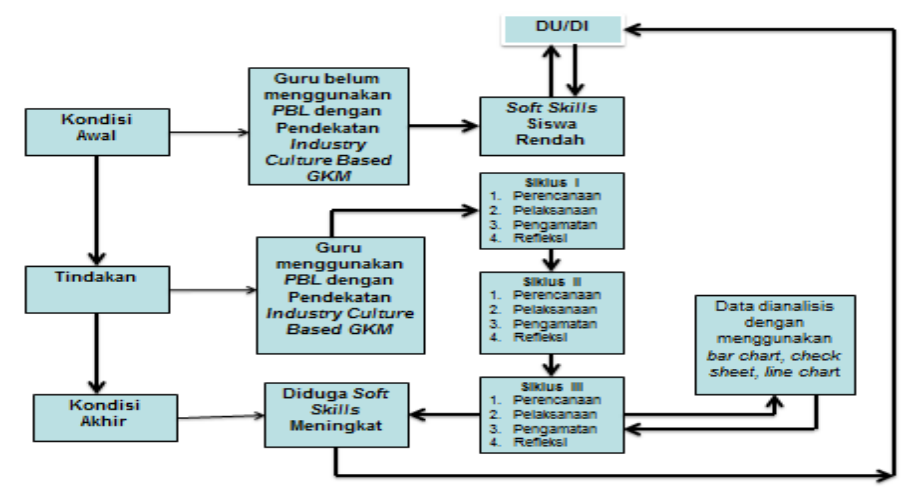

Gambar 3. Skema Alur Teknik Analisis Data

Keterangan gambar:

PBL $\quad$ : Project Based Learning

GKM : Gemba Kaizen Model

Tahapan Análisis Data Pada Variabel Pembelajaran Praktik dan Soft Skills.

Tahapan análisis data pada variabel pembelajaran praktik dan soft skills terdiri atas 7 tahapan yaitu:

1) Analisis professional and problem solving skill.

2) Analisis writing report skill.

3) Analisis self assessment.

4) Analisis $5 S$ tools.

5) Analisis waste tools.

6) Analisis teamwork skill.

7) Analisis communication skill.

Dalam tahapan analisis data tersebut di atas mengacu pada teknik analisis interaktif salah satu model teknik analisis kualitatif yang dikembangkan oleh Miles dan Huberman (1985) terdiri atas 3 komponen yang saling terkait satu sama lain: reduksi data, beberan (display) data, dan penarik kesimpulan. Reduksi data ini adalah proses menginput data instrumen pembelajaran praktik berupa tes praktik kemudian disusun dan dibedakan hasil tes praktik per-siklus. Setelah itu beberkan (display) masing-masing data per-siklus lalu buat analisis data menggunakan bar chart dan terakhir tarik kesimpulan.

Analisis data juga dilakukan pada setiap data yang dikumpulkan, baik data kuantitatif maupun data kualitatif. Berdasarkan jenis data, teknik analisis yang digunakan dideskripsikan sebagai berikut:

1) Data kuantitatif misalnya nilai hasil belajar siswa dapat dianalisis secara statistik deskriptif sederhana, yakni dengan rerata (mean), simpangan baku dan atau persentase (\%) yang diperoleh dari tes praktik, presentasi dan penilaian laporan kerja.

2) Data kualitatif yaitu data yang berupa informasi berbentuk kalimat yang memberi gambaran tentang ekspresi siswa terhadap tingkat pemahaman suatu mata pelajaran (kognitif), pandangan atau sikap siswa terhadap penggunaan media yang baru (afektif), aktivitas siswa dalam mengikuti pembelajaran, perhatian, antusias dalam belajar, kepercayaan diri, motivasi belajar dan sejenisnya diperoleh dari observasi, angket, $5 \mathrm{~S}$ tools, waste tools dan evaluasi diri.

\section{HASIL}

Berdasarkan hasil observasi, tes praktik, laporan kerja, presentasi, evaluasi diri, waste dan $5 S$ tool yang dilakukan pada siklus I, siklus II dan siklus III maka untuk melihat perbandingan hasilnya kita dapat analisis dengan menggunakan beberapa tools kualitas seperti bar chart, line chart dan check sheet dengan penjelasan sebagai berikut:

Analisis Data Professional and Problem Solving Skill dengan Bar Chart

Hasil analisa data perbandingan rata-rata nilai professional and problem solving skill pada siklus I, II dan III dapat dilihat pada Tabel 1. 
Tabel 1. Nilai Professional And Problem Solving Skill Siklus I, II dan III.

\begin{tabular}{|c|c|c|c|c|c|c|c|}
\hline \multirow{2}{*}{$\begin{array}{l}\text { Tindakan } \\
\text { Siklus }\end{array}$} & \multicolumn{9}{|c|}{$\begin{array}{c}\text { Rata-rata nilai komponen } \\
\text { Pengetahuan } \\
\text { (Skor 20) }\end{array}$} & $\begin{array}{c}\text { Persiapan } \\
\text { (Skor 10) }\end{array}$ & $\begin{array}{c}\text { Proses } \\
\text { (Skor 30) }\end{array}$ & $\begin{array}{c}\text { Hasil } \\
\text { (Skor 10) }\end{array}$ & $\begin{array}{c}\text { Sikap Kerja } \\
\text { (Skor 10) }\end{array}$ & $\begin{array}{c}\text { Waktu } \\
\text { (Skor 5) }\end{array}$ & (100) \\
\hline I & 17 & 9 & 18 & 8 & 24 & 2 & 78 \\
\hline II & 18 & 10 & 19 & 9 & 24 & 3 & 83 \\
\hline III & 20 & 10 & 19 & 10 & 25 & 5 & 89 \\
\hline
\end{tabular}

Kemudian analisis data perbandingan rata-rata nilai professional and problem solving skill divisualisasikan dalam bentuk bar chart seperti pada Gambar 4.

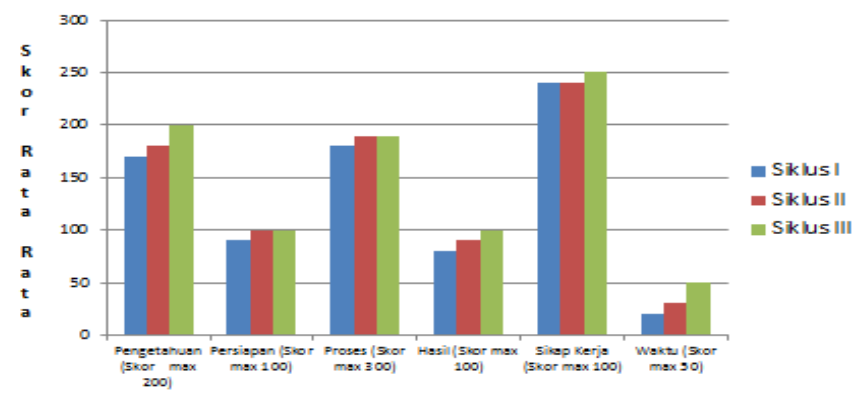

Gambar 4. Bar chart hasil analisis professional and problem solving skill pada siklus I, II dan III

Berdasarkan tampilan bar chart (Gambar 4) menunjukkan bahwa aspek penilaian pengetahuan mengalami peningkatan dimulai dari siklus I (Skor 17), II (Skor 18) dan III (Skor 20). Untuk aspek persiapan untuk siklus II (Skor 10) dan III (Skor 10) sudah sama indek warnanya artinya mengalami peningkatan di siklus I (Skor 9) saja pada saat siklus II dan III konstan. Sementara aspek proses hampir sama dengan aspek persiapan hanya saja siklus I-nya lebih rapat dibandingkan dengan aspek persiapan. Sebaliknya aspek hasil ada peningkatan secara signifikan dari siklus I (Skor 8), II (Skor 9) dan III (Skor 10) dan aspek sikap kerja di siklus I (Skor 24) dan II (Skor 24) indek warnanya berimpit hingga mulai meningkat kembali di siklus III (Skor 25). Dan yang lebih dari siklus I (Skor 2), II (Skor 3) dan III (Skor 5) kecepatan waktu kerjanya makin membaik diiringi kualitasnya sehingga secara keseluruhan skor akhir professional and problem solving skill dengan hasil rata-rata nilainya pada siklus I (Skor 78), siklus II (Skor 83) dan siklus III (Skor 89) ini menunjukkan bahwa siswa SMK Kampung Jawa ada peningkatan yang signifikan pada professional and problem solving skill.

\section{Analisis Data Writing Report Skill Dengan Bar Chart}

Hasil analisis data perbandingan rata-rata nilai writing report skill pada siklus I, II dan III dapat dilihat pada Tabel 2 .

Tabel 2. Perbandingan Nilai Writing Report Skill Pada Siklus I, II dan III.

\begin{tabular}{|c|c|c|c|c|c|c|}
\hline \multirow[b]{2}{*}{ Tindakan } & \multicolumn{5}{|c|}{ Rata-Rata Nilai Komponen } & Skor Akhir \\
\hline & $\begin{array}{l}\text { Tata Tulis } \\
\text { (Skor 20) }\end{array}$ & $\begin{array}{c}\text { Judul } \\
\text { (Skor } 10 \\
\text { ) }\end{array}$ & $\begin{array}{l}\text { Bahan \& Alat } \\
\text { (Skor 10) }\end{array}$ & $\begin{array}{c}\text { SOP } \\
(\text { Skor 40) }\end{array}$ & $\begin{array}{l}\text { Estimasi } \\
\text { (Skor 20) }\end{array}$ & $(100)$ \\
\hline Siklus I & 15 & 8 & 7 & 31 & 16 & 77 \\
\hline Siklus II & 17 & 9 & 9 & 33 & 17 & 85 \\
\hline Siklus III & 19 & 9 & 10 & 34 & 17 & 89 \\
\hline
\end{tabular}

Kemudian analisis data perbandingan rata-rata nilai writing report skill divisualisasikan dalam bentuk bar chart seperti pada Gambar 5. 


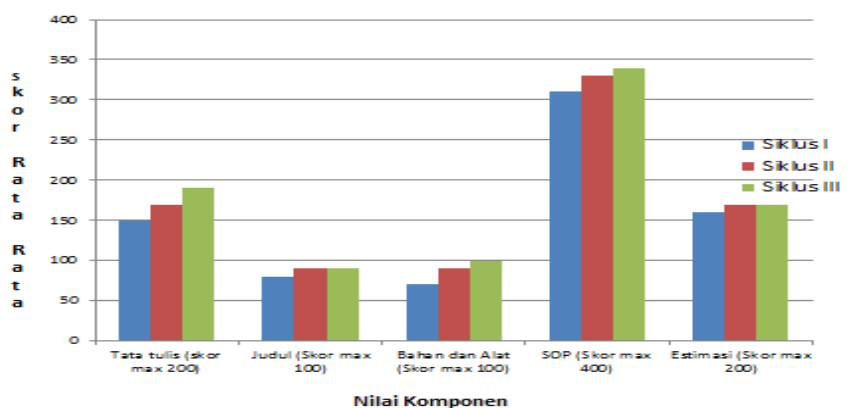

Gambar 5. Bar Chart Hasil Analisis Writing Report Skills Siklus I, II dan III.

Berdasarkan tampilan bar chart (Gambar 5) menunjukkan bahwa aspek untuk penilaian tata tulis mengalami peningkatan walaupun hanya sedikit demi sedikit dengan peningkatan mulai dari siklus I (Skor 15), II (Skor 17) dan III (Skor 19). Kemudian penilaian judul ada peningkatan dari siklus I (Skor 8) ke siklus II (Skor 9) ketika sampai siklus ke-III nya konstan seperti pada siklus II. Sebaliknya dari segi aspek bahan alat hampir sama dengan aspek judul hanya kenaikan lebih baik dibandingkan pada aspek judul. Sementara aspek pembuatan SOP dari siklus I (Skor 31), II (Skor 33) dan III (Skor 34) mengalami kenaikan sedikit demi sedikit dan aspek membuat estimasi (membuat kesimpulan) dari siklus I (Skor 16) kemudian ada perubahan kenaikan pada siklus II (Skor 17) hingga bertahan terus pada siklus III (Skor 17), sehingga secara keseluruhan skor akhir writing report skill dengan hasil rata-rata nilainya pada siklus I (Skor 77), siklus II (Skor 85) dan siklus III (Skor 89) ini menunjukkan bahwa siswa SMK Kampung Jawa sudah baik dalam membuat laporan kerja.

\section{Analisis Data Self Assessment Dengan Pareto Diagram}

Hasil analisis data perbandingan rata-rata nilai prosentase self assesment siswa pada siklus I, II dan III dapat dilihat pada Tabel 3.

Tabel 3. Perbandingan Nilai Prosentase Self Assessment Siklus I, II dan III

\begin{tabular}{|l|c|c|c|c|c|c|}
\hline \multirow{3}{*}{ Tindakan } & \multicolumn{5}{|c|}{ Prosentase Hasil Self Assesment } \\
\cline { 2 - 6 } & $\begin{array}{c}\text { Menggunakan seragam kerja } \\
\text { yang bersih }\end{array}$ & \multicolumn{2}{c|}{ Menggunakan APD } & \multicolumn{2}{c|}{ Kelengkapan administrasi personal } \\
\cline { 2 - 6 } & Ya & Tidak & Ya & Tidak & Ya & Tidak \\
\hline Siklus I & $21,12 \%$ & $78,88 \%$ & $18,96 \%$ & $81,03 \%$ & $100 \%$ & $0 \%$ \\
\hline Siklus II & $85,56 \%$ & $14,44 \%$ & $77,59 \%$ & $22,41 \%$ & $100 \%$ & $0 \%$ \\
\hline Siklus III & $100 \%$ & $0 \%$ & $88,79 \%$ & $11,21 \%$ & $100 \%$ & $0 \%$ \\
\hline
\end{tabular}

Kemudian analisis data perbandingan rata-rata nilai self assesment divisualisasikan dalam bentuk bar chart seperti pada Gambar 6.

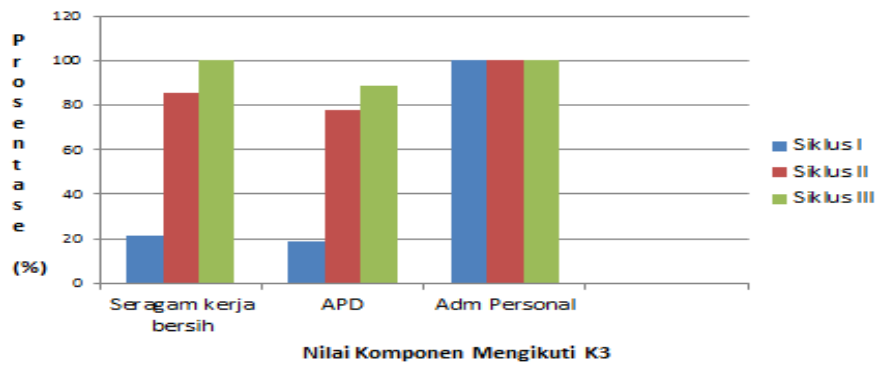

Gambar 6. Bar Chart Hasil Analisis Self Assesment Siklus I, II dan III 
Berdasarkan tampilan bar chart (Gambar 6) menunjukkan bahwa self assessment mengikuti prosedur K3 pada aspek menggunakan pakaian kerja (wearpack) yang bersih ada peningkatan secara signifikan dari siklus I (21,12\%), II (85,56 \%), III hingga $100 \%$ begitupun mengunakan alat pengaman diri (APD) walaupun baru sampai sekitar $88,79 \%$ pada siklus III. Sementara administrasi personal dari siklus I, II, dan III sudah pada pencapaian $100 \%$ sehingga secara keseluruhan siswa SMK Kampung Jawa sudah cukup dikatakan dapat mengikuti prosedur K3 dengan baik.

\section{Analisis Data 5S Tools Dengan Line Chart}

Hasil analisis data perbandingan prosentase rata-rata siswa yang menerapkan $5 \mathrm{~S}$ pada siklus I, II dan III dapat dilihat pada Tabel 4.

Tabel 4. Posentase rata-rata siswa menerapkan 5 S pada siklus I, II dan III.

\begin{tabular}{|l|c|c|c|c|c|}
\hline \multirow{2}{*}{ Tindakan } & \multicolumn{5}{|c|}{ Prosentase Komponen 5S } \\
\cline { 2 - 6 } & Seiri (\%) & Seiton (\%) & Seiso (\%) & Seiketsu (\%) & Shitsuke (\%) \\
\hline Siklus I & 44,82 & 44,83 & 70,88 & 59,77 & 65,52 \\
\hline Siklus II & 74,43 & 71,84 & 84,67 & 76,44 & 79,31 \\
\hline Siklus III & 91,94 & 90,80 & 96,55 & 79,31 & 91,38 \\
\hline
\end{tabular}

Sumber: Data Nilai $5 S$ tools

Kemudian analisis data perbandingan data perbandingan prosentase rata-rata siswa yang menerapkan 5S pada siklus I, II dan III divisualisasikan dalam bentuk line chart seperti pada Gambar 7.

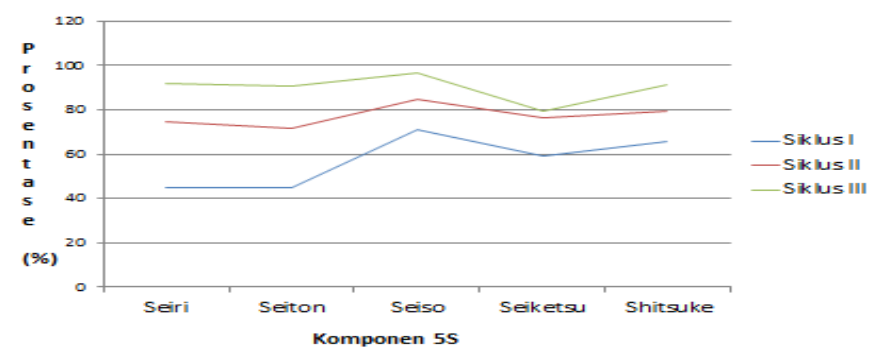

Gambar 7. Line chart hasil analisis $5 \mathrm{~S}$ tools Siklus I, II dan III

Berdasarkan tampilan line chart diatas (Gambar 4.8) menunjukkan bahwa kriteria 5S seperti seiri pada siklus I (44,82\%), II (74,43 \%) dan III (91,94\%), seiton pada siklus I (44,83 \%), II $(71,84 \%)$ dan III $(90,80 \%)$, seiso pada siklus I $(70,88 \%)$, II $(84,67 \%)$ dan III $(96,55 \%)$, seiketsu pada siklus I $(59,77 \%)$, II (76,44\%) dan III (79,31\%) serta shitsuke pada siklus I $(65,52$ $\%)$, II (79,31 \%) dan III (91,38 \%) rata-rata mengalami kenaikan hingga $20 \%$ dari tiap-tiap siklus I, II hingga III artinya bahwa kesadaran siswa SMK Kampung Jawa dalam menerapkan 5S naik secara berturut-turut.

\section{Analisis Data Waste Tools Dengan Check Sheet}

Hasil analisis data perbandingan temuan waste ditiap-tiap kompetensi pada siklus I, II dan III dapat dilihat pada Tabel 5 .

Tabel 5. Daftar check sheet hasil waste tools pada siklus I, II dan III

\begin{tabular}{|c|c|c|c|c|c|c|c|c|c|}
\hline \multirow{2}{*}{ ITEM WASTE } & \multicolumn{3}{|c|}{ SIKLUS I } & \multicolumn{3}{c|}{ SIKLUS II } & \multicolumn{3}{c|}{ SIKLUS III } \\
\cline { 2 - 10 } & $\begin{array}{c}\text { TUNE } \\
\text { EFI }\end{array}$ & $\begin{array}{c}\text { O/H } \\
\text { ENGI } \\
\text { NE }\end{array}$ & $\begin{array}{c}\text { BRAKE } \\
\text { SYSTEM }\end{array}$ & $\begin{array}{c}\text { TUNE } \\
\text { EFI }\end{array}$ & $\begin{array}{c}\text { O/H } \\
\text { ENGIN } \\
\text { E }\end{array}$ & $\begin{array}{c}\text { BRAKE } \\
\text { SYSTEM }\end{array}$ & $\begin{array}{c}\text { TUNE } \\
\text { EFI }\end{array}$ & $\begin{array}{c}\text { O/H } \\
\text { ENGINE }\end{array}$ & $\begin{array}{c}\text { BRAKE } \\
\text { SYSTEM }\end{array}$ \\
\hline MUDA & 130 & 259 & 216 & 38 & 122 & 86 & 2 & 58 & 59 \\
\hline MURA & 45 & 216 & 140 & 22 & 110 & 140 & 2 & 27 & 93 \\
\hline MURI & 17 & 105 & 35 & 2 & 44 & 35 & 0 & 15 & 20 \\
\hline $\begin{array}{c}\text { JUMLAH } \\
\text { TOTAL }\end{array}$ & $\mathbf{1 9 2}$ & $\mathbf{5 8 0}$ & $\mathbf{3 9 1}$ & $\mathbf{6 2}$ & $\mathbf{2 7 6}$ & $\mathbf{2 6 1}$ & $\mathbf{4}$ & $\mathbf{1 0 0}$ & $\mathbf{1 7 2}$ \\
\hline
\end{tabular}


Berdasarkan daftar check list waste pada Tabel 5 item waste dari siklus I dengan kompetensi yang berbeda mengalami penurunan pemborosan (waste) baik muda, mura maupun muri hingga mencapai $75 \%$ penurunan sampai dengan ke siklus III. Dengan begitu efek yang dirasakan adalah proses improvement continuous (perbaikan terus-menerus) tentunya dengan melalui proses yang berkualitas dan banyak keuntungan yang didapat diantaranya: tool dan equipment service awet dan terpelihara dengan baik, waktu jadi dipercepat dengan kualitas yang tepat, mesin tahan lama, keadaan bengkel selalu tertata rapi dan bersih sehingga dari perlakuan mencari waste para siswa SMK Kampung Jawa memahami kaizen dalam pekerjaan maupun dalam kehidupan sehari-hari.

\section{Analisis Data Teamwork Skill Dengan Check Sheet}

Hasil analisa data perbandingan teamwork skill pada siklus I, II dan III dapat dilihat pada Tabel 6.

Tabel 6. Check List Analisis Hasil Teamwork Skill Siklus I, II dan III

\begin{tabular}{|c|l|c|c|c|c|c|c|c|c|c|c|c|c|}
\hline \multirow{2}{*}{ No. } & \multicolumn{1}{|c|}{ Aspek Yang Diamati } & \multicolumn{4}{|c|}{ Siklus I } & \multicolumn{5}{|c|}{ Siklus II } & \multicolumn{5}{|c|}{ Siklus III } \\
\hline & & BS & B & C & K & BS & B & C & K & BS & B & C & K \\
\hline 1 & $\begin{array}{l}\text { Mau bekerja sama } \\
\text { (cooperative) }\end{array}$ & & & $\sqrt{ }$ & & & $\sqrt{ }$ & & & & $\sqrt{ }$ & & \\
\hline 2 & $\begin{array}{l}\text { Mengungkapkan harapan yang } \\
\text { positif }\end{array}$ & & & & $\sqrt{ }$ & & & $\sqrt{ }$ & & & $\sqrt{ }$ & & \\
\hline 3 & Menghargai masukan & & & & $\sqrt{ }$ & & & $\sqrt{ }$ & & & $\sqrt{ }$ & & \\
\hline 4 & Memberikan dorongan & & & & $\sqrt{ }$ & & & $\sqrt{ }$ & & & $\sqrt{ }$ & & \\
\hline 5 & $\begin{array}{l}\text { Membangun semangat } \\
\text { kelompok }\end{array}$ & & & $\sqrt{ }$ & & & & $\sqrt{ }$ & & $\sqrt{ }$ & & & \\
\hline
\end{tabular}

Berdasarkan daftar check sheet pada Tabel 6 siklus I teamwork skill baru mencapai $62 \%$ artinya para siswa belum menampakkan kerja tim masih berfokus pada diri sendiri, rasa menghargai, memberikan dorongan yang positif masih kurang sementara membangun kelompok dengan yel-yel masih ragu-ragu dengan kemampuan dirinya. Kemudian pada siklus II team skill mulai naik sedikit pada kisaran 68 \% diartikan para siswa sudah mulai mau bekerjasama, perlahan tapi pasti secara interpersonal dan aksinya sudah mulai terlihat dalam memberikan dorongan, membangun semangat kelompok. Pada siklus III teamwork skill mencapai $81 \%$ ini berarti sudah mulai ada peningkatan dibandingkan pada siklus II kerja tim lebih baik secara interpersonal dan aksinya.

\section{Analisis Data Communication Skill Dengan Bar Chart}

Hasil analisis data perbandingan rata-rata nilai communication skill pada siklus I, II dan III dapat dilihat pada Tabel 7.

Tabel 7. Perbandingan Nilai Communication Skill Siklus I, II dan III.

\begin{tabular}{|l|c|c|c|c|}
\hline \multirow{2}{*}{ Tindakan } & \multicolumn{3}{|c|}{ Rata-rata nilai komponen } & $\begin{array}{c}\text { Skor } \\
\text { Akhir }\end{array}$ \\
\cline { 2 - 5 } & $\begin{array}{c}\text { Tampilan Slide } \\
\text { (Skor 10) }\end{array}$ & $\begin{array}{c}\text { Kemampuan Verbal } \\
\text { (Skor 60) }\end{array}$ & $\begin{array}{c}\text { Isi Materi } \\
\text { (Skor 30) }\end{array}$ & (100) \\
\hline Siklus I & 7 & 49 & 21 & 77 \\
\hline Siklus II & 9 & 54 & 22 & 85 \\
\hline Siklus III & 10 & 55 & 23 & 87 \\
\hline
\end{tabular}

Kemudian analisis data perbandingan rata-rata nilai communication skill divisualisasikan dalam bentuk bar chart seperti pada Gambar 8. 


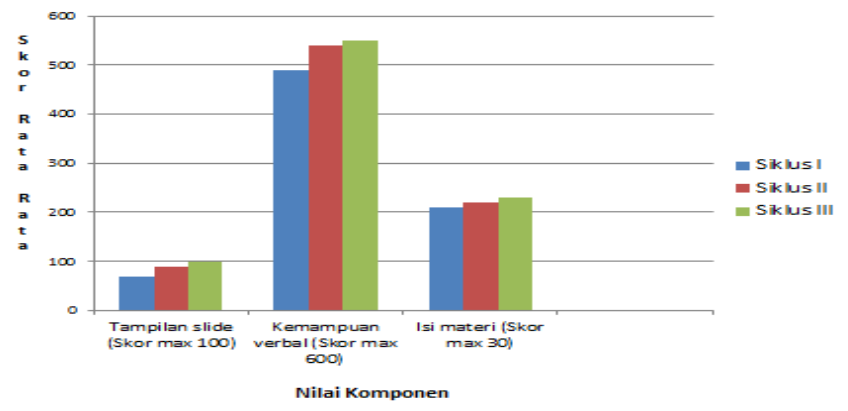

Gambar 8. Bar Chart Hasil Analisis Communication Skill Siklus I, II dan III .

Berdasarkan tampilan bar chart menunjukkan bahwa kriteria communication skill seperti tampilan slide pada siklus I (Skor 7), II (Skor 9) dan III (Skor 9) mengalami peningkatan yang berarti. Kemudian penilaian kemampuan verbal siklus I (Skor 49), II (Skor 54), III (Skor 55) berturut-turut naik namun tidak terlalu banyak kenaikannya jika dilihat dari rapatnya garis sementara pada penilaian isi materi siklus I (Skor 21), II (Skor 22) dan III (Skor 23) juga ada peningkatan walaupun perbedaan hanya sedikit sehingga secara keseluruhan skor akhir communication skill hasil rata-rata nilainya pada siklus I (Skor 77), siklus II (Skor 85) dan siklus III (Skor 87) ini menunjukkan bahwa siswa SMK Kampung Jawa cukup baik dalam penggunaan bahasa sebagai komunikasi teknik.

\section{PEMBAHASAN}

\section{Pencapaian Keberhasilan dari Aspek Soft Skill}

Berdasarkan analisis ketiga siklus aspek soft skills yang mengalami peningkatan secara signifikan adalah communication skill secara berturut-turut baru writing report skill, professional and problem solving skill, personal quality dan teamwork skill. Pencapaian keberhasilan communication skill mencakup kemampuan berbicara baik, mendengarkan dengan baik, memberi dan memahami instruksi, serta berkomunikasi dalam cara-cara sesuai dengan situasi dan audiennya. Kepercayaan diri siswa dalam mempresentasi suatu proyek menjadi ukuran keberhasilan dalam mencapai target communication skill.

Dalam membuat laporan kerja secara sistematis dan terencana menjadikan bahasa komunikasi teknik sebagai target keberhasilan writing report skill. Kemudian professional and problem solving skill mencakup kemampuan kejuruan dalam bidang tekniknya ditambah dengan kemampuan memecahkan masalah dengan melakukan identifikasi masalah, perumusan dan evaluasi dengan berbagai solusi alternatif terhadap masalah dengan risiko berat sekalipun dan menguntungkan dengan tidak sia-sia dalam pekerjaannya adalah juga menjadi target dari soft skill ini.

Teamwork skill pencapaian keberhasilannya adalah pembentukan tim yang solid dan tanggap dalam pekerjaannya ketika mendapat proyek mereka sudah terencana mengerti apa dan siapa yang harus mengerjakan, dapat bekerja baik dengan orang lain, berpartisipasi sebagai anggota tim menyelesaikan konflik yang berat. Akhirnya secara keseluruhan siswa dapat beradaptasi dengan baik dan tepat sesuai budaya industri.

\section{Implikasi Industri}

Berdasarkan temuan utama pada penelitian ini ditunjukkan bahwa aspek soft skills berbasis gemba kaizen sangat penting dan berpengaruh dalam proses pembelajaran praktik serta memberikan implikasi sendiri terutama dalam pembentukan keterampilan seseorang dalam mengatur dirinya sendiri, hubungan dengan orang lain untuk pengembangan kerja secara optimal dan berperilaku kualitas oleh karena itu, pengembangan dan rencana tindak lanjut pembelajaran praktik berorientasi soft skills melalui project based learning dengan pendekatan industrial culture based gemba kaizen agar tetap lestari dan terus dapat direalisasikan maka SMK Kampung Jawa mengupayakan: 
a) Pemodelan pembelajaran praktik berbasis gemba kaizen diimplementasikan pada setiap tingkatan kelas melalui kebijakan sekolah dengan penanggung jawab ketua kompetensi keahlian masing-masing.

b) Pembentukan soft skills siswa melintas dan terintegrasi pada semua mata pelajaran.

c) Penerapan budaya industri di sekolah sebagai habit dan cikal bakal dari konsep gemba kaizen agar terus dilestarikan dan dikembangkan.

d) Adanya lomba improvement tingkat kelas pada beberapa tema pelajaran dan kehidupan.

\section{KESIMPULAN}

Setelah semua tahap penelitian dilakukan, mulai dari pengkajian teori, penyusunan instrument penelitian sampai dengan pengumpulan data, pengolahan dan analisis data. Pada akhirnya penulis dapat menyimpulkan hasil penelitian tentang perbaikan pembelajaran praktik berorientasi soft skills dengan pendekatan industrial culture based gemba kaizen model yakni; Pertama, bahwa rumusan bentuk model pembelajaran praktik yang sesuai dalam pembentukan dan peningkatan kemampuan soft skills siswa SMK Kampung Jawa adalah model pembelajaran praktik dengan pendekatan industrial culture based gemba kaizen; Kedua, aspek soft skills yang memuat communication skill, writing report skill, professional and problem solving skill, personal quality dan teamwork skill penting diberikan kepada siswa sebagai materi utama yang terintegrasi pada semua mata pelajaran dan diimplementasikan pada kegiatan sehari-hari ataupun melalui kegiatan yang terprogram dengan baik yang mendukung terbentuknya suasana dan lingkungan pendidikan berbasis kualitas; Ketiga, pembelajaran berbasis proyek dengan pendekatan budaya industri gemba kaizen sangat cocok dan relevan untuk pendidikan teknik; Keempat, bahwa dengan perbaikan pembelajaran praktik beorientasi soft skills ternyata memberikan respon positif pada pembentukan soft skills siswa terbukti dengan adanya kenaikan ketuntasan kemampuan soft skills secara signifikan baik pada siklus I, II dan III dengan hasil yang lebih dominan pada communication skill dan writing report skill berturut-turut pada professional and problem solving skill, personal quality dan teamwork skill.

\section{Daftar Pustaka}

Al-Abduwani, T. A. R. (2012). The value and development of soft skills: the case of Oman. International Journal of Information Technology and Business Management.

Art of Lean, Inc. (2014). Toyota production system basic Hand Book. Retrieved from www.artoflean.com.

Astra Daihatsu Motor, PT. (2008). Daihatsu technician. Training Center Technical Servive Division, Jakarta: Service Training Departement.

Baroto, Joko. (2014). Membangun soft Skill di SMK Makalah Seminar Sinergi PT Astra Daihatsu Motor dengan Dunia Pendidikan untuk Menyonsong AFTA 2015. Dinas Pendidikan Provinsi DKI Jakarta.

Bell, S. (2010). Project-based learning for the 21st century: Skills for the future. The Clearing House, 83(2), 39-43.

Campbell. (2012). Soft skills for work. The NWT Literacy Council. Retrieved from www.nwt.literacy.ca.

Caspersen, J., de Lange, T., Prøitz, T. S., \& Solbrekke, T. D. Leaning About Quality.

Daiya, B. K. (2012). Applying Gemba Kaizen at SKS Separator in cement plant: A case study. IOSR Journal of Engineering, 1-6.

Djojonegoro, Wardiman. (2014). Pengembangan kerja sama dunia kerja dengan SMK Makalah Seminar Sinergi PT Astra Daihatsu Motor dengan Dunia Pendidikan untuk Menyonsong AFTA 2015. Dinas Pendidikan Provinsi DKI Jakarta.

Kementrian Pendidikan Nasional. (2011). Pedoman pelaksanaan pendidikan karakter. Jakarta: Balitbang Pusbukur.

Kementrian Pendidikan dan Kebudayaan. (2014). Pedoman Penilaian Ujian Praktik, Jakarta: BNSP. 
Khedkar, S. B., Thakre, R. D., Mahantare, Y. V., \& Gondne, M. R. (2012). Study of Implementing 5S Techniques in Plastic Moulding Industry.

NHS Institute for Innovation and Improvement. (2010). The handbook of quality and service improvement tools. Retrieved from www.institute.nhs.uk.

Panasan, Mookdaporn ., \& Nuangchalerm Prasart. (2010). Learning outcomes of project-based and inquiry-based learning activities. Journal of Social Sciences, 6 (2): 252-255.

Pemerintah Republik Indonesia. (2010). Kebijakan Nasional: Pembangunan Karakter Bangsa Tahun 2010-2025.

Taggart, M., Koskela, L., \& Rooke, J. (2014). The role of the supply chain in the elimination and reduction of construction rework and defects: an action research approach. Construction Management and Economics, 32(7-8), 829-842.

Teplická, K., \& Čulkova, K. (2011). Kaizen and its applying during cost decreasing in process of production firm maintenance. Annals of Faculty Engineering Hunedoara, 9(3), 2011.

Suhardjono. (2011). Penelitian tindakan kelas dan sekolah, Malang : Cakrawala Indonesia LP3 Universitas Negeri Malang.

Rais, M. (2010). Project-Based Learning : Inovasi Pembelajaran yang Berorientasi Soft Skills. In Proseding Seminar Nasional Pendidikan Teknologi dan Kejuruan Fakultas Teknik Universitas Negeri Surabaya.

World Economic Forum. (2014). The Global competitiveness report 2014-2015, Geneva: Worl Economic Forum. 